\title{
COVID-19 recovery measures and use of medications among COVID-19 patients at home: A cross- sectional study in Bangladesh
}

\author{
Abdullah Al Noman \\ BioScience Academy Bangladesh \\ Taufique Joarder \\ Public Health Foundation \\ Md. Shofiqul Islam \\ BioScience Academy Bangladesh \\ Md. Sabbir Hossain \\ Centre for Policy Dialogue \\ Samia Sadaf \\ University of Chittagong \\ Md. Abdullah Al Noman \\ LABAID Specialized Hospital \\ Nazmus Sakib \\ BioScience Academy Bangladesh \\ Jannatul Efte Ekra \\ BioScience Academy Bangladesh \\ Md. Sujan Islam \\ BioScience Academy Bangladesh \\ Rima Islam Meem \\ BioScience Academy Bangladesh \\ Samiron Sana \\ Mawlana Bhashani Science and Technology University \\ Mohammad Meshbahur Rahman ( $\nabla$ meshbahur.rahman@brfbd.org) \\ World University of Bangladesh
}

\section{Research Article}

Keywords: Home Health-seeking, Recovery measures, Recovery time, COVID-19, Bangladesh

Posted Date: June 7th, 2021

DOI: https://doi.org/10.21203/rs.3.rs-593949/v1

License: @ (i) This work is licensed under a Creative Commons Attribution 4.0 International License. Read Full License 


\section{Abstract}

Background The COVID-19 is the greatest catastrophe of the 21 st century that ravaged health, economy, and everyday life. Over $90 \%$ of the infected individuals in Bangladesh took home treatments following various approaches and consuming different medications. The study aims to identify the recovery measures and the medications used by COVID-19 patients at home. Methods An online-based, cross-sectional survey was conducted between 5 October 2020 and 5 January 2021 among the COVID-19 patients who did not seek care from hospitals and recovered at home. Participants from all the administrative divisions of Bangladesh were recruited via social media. After obtaining consent, subjects were enrolled to complete the questionnaire that included questions on demographic characteristics, clinical itinerary, non-pharmacological and pharmacological approaches. Results of the 241 respondents, the majority were males (64.3\%), aged 21-30 years (42.3\%), and urban residents (65.6\%). Fever (92.5\%), cough $(78.4 \%)$, and sore throat (62.7\%) were the most common symptoms. Hypertension (17.3\%), allergic rhinitis (15.3\%), and asthma (15.3\%) were the most prevalent pre-existing chronic conditions. Most of the respondents adopted some non-pharmacological approaches, such as inhaling steam/gargling warm water (75.1\%), drinking any hot drink (85.9\%), and consuming vegetables and fruits $(67.6 \%)$ daily. Among the medicines consumed, paracetamol was the highest $(97.1 \%)$, followed by antihistamines $(77.6 \%)$ and antibiotics $(61.4 \%)$ while corticosteroid, antiparasitic and antiviral drugs were less consumed drugs. Binary logistic regression found, living in the urban area, level of education and pre-existing diabetes were significant factors that impact recovery time from the COVID-19. Conclusions Most of the individuals experienced mild to moderate symptoms and used non-pharmacological approaches, while over-the-counter drugs were the most consumed medicines. Though these measures did not contribute significantly to recovery time, these can be used as a form of home management in the early stage to reduce the disease severity and may be effective for mild and moderate patients.

\section{Background}

Since December 2019, the world has succumbed to a deadly virus named Severe Acute Respiratory Syndrome Coronavirus-2 (SARS-CoV-2). This virus has spread worldwide and caused a devastating coronavirus pandemic later announced as Coronavirus disease-2019 (COVID-19) by the World Health Organization (WHO) [1]. Almost all the countries worldwide are facing its ramification, and more than 170 million individuals have been infected while over 3.5 million of them have died as of 1 June 2021 [2]. This single-stranded enveloped RNA virus belongs to the genus betacoronavirus and has a genetic similarity with two previously discovered viruses SARS-CoV and MERS-CoV, though it has a high infection rate compared to the later ones [3]. As an RNA virus, SARS CoV-2 demonstrated high genomic variations and infected many people even after taking precautionary measures.

Bangladesh is also facing this unavoidable outbreak with 802,305 confirmed cases and 12,660 deaths so far till 1 June 2021 [4]. The "Second wave" has struck the country severely from the end of March 2021 and broken all the records of confirmed cases. Between 29 March 2021 and 4 April 2021, the country recorded a $67.7 \%$ increase in COVID-19 patients with 41650 confirmed cases [5]. The government had to impose lockdown again from 30 March 2021 in response to the second wave [6]. There is a lack of testing kits, PPE, masks, and infrared thermometers in the country [7]. Although the infection was rising, the number of COVID-19 dedicated beds was decreasing. There were 9,807 general beds as of $28 \mathrm{March} 2021$, whereas there were 10,474 beds on 21 March 202, [8,9]. When the survey commenced, only 13,356 COVID-19 patients out of 88,993 patients were taking treatment at hospitals, whereas more than $80 \%$ of patients were taking treatment at home [10]. Centralized policy and inequality in the health care facilities compel the majority of the patients to take care at home. There was no specialized hospital in most divisions, while $34 \%$ of the total COVID-19 dedicated general beds were in Dhaka city, and 2,542 out of 3,329 of them are occupied [8]. Therefore, despite the intention of going to hospitals, many infected individuals could not get to the hospital facilities and developed a preference for taking medications at home Studies demonstrated pervasive mistrust of the Bangladeshi people on the health systems and healthcare providers during the COVID-19 pandemic [11, 12]. This distrust had made people reluctant to seek medical treatment at the hospital, and as a result, a lot of COVID-19 related deaths occurred outside hospitals; 696 people died outside hospitals, of which 662 have died at home by 22 September 2020 [13]. Moreover, this unprecedented pandemic massively disrupted the economy and raised poverty to $40.9 \%$ in 2020 , only $20.5 \%$ in 2019 . This poverty again made it difficult for many people to afford hospital treatment [14].

It has become the 'new normal,' and preventive measures such as washing hands, wearing masks, maintaining social and physical distancing have become the regular do's in our life. So, it is equally important to know what types of approaches were taken and which medicines were consumed by the COVID-19 patients at home. Many epidemiologists and infectious disease experts have warned that this novel disease will not go away soon, and people may have to adapt to this [15]. Though the virus is highly infectious, the preponderance of the patients had mild to moderate symptoms and recovered without special care and was recommended to take treatments at home. Due to the unavailability of any effective option and promising vaccine, infected individuals who did not require hospitalization were recommended to strengthen their immunity and follow home remedies. Many news/information was circulated on social media and the internet, claiming various unproven treatments and approaches to be effective [16-19]. We, therefore, intended to conduct an online cross-sectional survey to identify some adopted practices and approaches, and consumed medications by COVID-19 patients at home who did not seek treatment from hospitals. These results will provide a glimpse of followed approaches and consumed medications by people as a form of home management. These measures can also be considered for the management of mild patients who would recover without hospital care.

\section{Methods}


This cross-sectional, online population-based survey was carried out from 15 October 2020 to 5 January 2021 among the COVID-19 patients who recovered without any hospital treatment by following home remedies, practices, and taking medications. The respondents were reportedly be infected during the first wave between March 2020 and November 2020 [1]. The convenience sampling method was applied to recruit the survey participants. Considering the situation and lockdown, the enumerators could not conduct a community-based study, but the enumerators were chosen to ensure representatives from all the divisions. The criteria for including participants were willing to participate, being a Bangladeshi resident, having access to the internet, and was recovered by taking treatment at home. The exclusion criteria were incomplete form, and participants recovered by taking treatment from medical facilities. A total of 271 potential respondents provided consent, but 241 who completed the entire survey, were included finally with a response rate of nearly $89 \%$.

\section{Data collection instrument}

A semi-structured questionnaire was designed using the Google Form. The questionnaire was in both Bangla and English that are the two most commonly used languages in Bangladesh. A standardized general description of the survey was given in both languages before the link was provided. Participants willing to participate were directed to the questionnaire after giving consent by clicking the 'Yes' option. The final questionnaire had four sections; six questions regarding the socio-demographic characteristics and seven questions to identify the clinical features of the patients, such as COVID-19 symptoms and existing comorbidities. The clinical symptoms were selected as per the Centers for Disease Control and Prevention (CDC) guidelines [20]. The third section consisted of five questions to identify the practices, including eating vegetables and fruits, drinking hot drinks (such as tea) and taking vitamin supplements. The remedies and approaches were selected based on national guidelines on clinical management of COVID-19 of the country and WHO COVID-19 recommendations [21-23]. The final section was to know about the types of medication such as paracetamol, antibiotic and antiviral drugs taken by the respondents to cure or relieve the symptoms. With some brand name examples, a brief Bangla explanation was attached to questions regarding medications for a better understanding. The questionnaire was tested on a sample of five people to identify any ambiguous and difficult questions. The questions thus identified were either reformulated or eliminated. Two experts reviewed the initial draft of the questionnaire for validation. Independent variables were: socio-demographic characteristics, clinical conditions, practices, and medications.

\section{Data collection procedures}

The Google Form was shareable through online platforms like Facebook, Messenger, and WhatsApp. The form was also shared in various Facebook groups dedicated to COVID-19 related information. Most participants who shared their experience on social media were contacted personally through messenger or phone call for data collection. The respondents were also encouraged to share the form with eligible participants. In the case of illiterate respondents, other family members assisted them in responding to the questionnaire. Consent was obtained before starting the survey, and confidentiality was maintained.

\section{Ethical considerations}

Ethical Review Committee of the Public Health Foundation, Bangladesh (Reference number: PHFBD/ERC/03/2021) approved this study. All participants were provided with an informed consent form that concisely described the purpose, aims, and procedure of the research, and confidentiality of the information was strictly maintained.

\section{Statistical analysis}

Descriptive analysis was performed to present frequency and percentages. Previous studies showed that clinical recovery time for mild patients is approximately two weeks and for severe or critical patients is 3-6 weeks [24, 25]. We measured the recovery time from the time of being tested positive since the respondents may not be sure of the onset of their symptoms. The recovery time was categorized into early recovery, recovery within two weeks (coded as 1), and late recovery, i.e., more than 14 days (coded as 0 ). We applied the binary logistic regression model to determine the most relevant factors that might significantly influence COVID-19 recovery time.

In this study, the variable selection procedure for the logistic regression model was done in two stages. In the first stage, the Pearson Chi-square test was carried out primarily to select the variables with a strong association with recovery time from COVID-19. Out of the thirty-four variables, seven variables are primarily selected at a $10 \%$ significance level. In the second stage, a binary logistic regression model was performed with the selected seven variables, and the most significant variables with their adjusted odds ratio were extracted at a 5\% significance level [26]. The classification table was used to evaluate the predictive accuracy of the final model. The Hosmer and Lemeshow goodness-of-fit (GOF) test was also applied to provide a statement of the overall fit of the final model. Microsoft Excel 2016 was used for editing, sorting, and coding. All statistical analysis and data management were performed using SPSS (IBM SPSS version 25.0) data analysis software.

\section{Results}


Among the 241 participants completing the survey, males constitute about $64.3 \%$, and females $35.7 \%$. Most of the respondents were youth aged between 21 and 30 years (42.3\%), followed by younger adults of 31 to 40 years. Representatives from all divisions participated in the survey; most were from the Khulna division (17.4\%) and Dhaka division (14.5\%). The lowest participation was from the Rangpur division (10.0\%). People belonging to the urban area responded more than the rural ones. The highest percentage of the respondents had tertiary education (57.3\%), and $6.2 \%$ had no formal education. They were classified into three categories based on per capita daily income (ADB 2010) [27]. The 'low-income' group was people earning < 5088 BDT per month, the 'middle-income' group was people earning 5088-50880 BDT per month, and people with above 50880 BDT per month were categorized as the 'high-income' group (\$1 equivalent to 84.80 BDT, Accessed 23 February 2021). The majority of the participants belonged to the middle-income group (81.7\%). The detailed socio-demographic features have been described in Table 1.

Table 1. Socio-demographic characteristics of respondents $(\mathrm{N}=241)$.

\begin{tabular}{|c|c|c|}
\hline Variables & Frequency & Percentage \\
\hline \multicolumn{3}{|l|}{ Gender } \\
\hline Male & 155 & 64.3 \\
\hline Female & 86 & 35.7 \\
\hline \multicolumn{3}{|l|}{ Age } \\
\hline $0-20$ & 24 & 10.0 \\
\hline $21-30$ & 102 & 42.3 \\
\hline $31-40$ & 40 & 16.6 \\
\hline $41-50$ & 28 & 11.6 \\
\hline $51-60$ & 32 & 13.3 \\
\hline More than 60 & 15 & 6.2 \\
\hline \multicolumn{3}{|l|}{ Division } \\
\hline Barishal & 31 & 12.9 \\
\hline Chattogram & 26 & 10.8 \\
\hline Dhaka & 35 & 14.5 \\
\hline Khulna & 42 & 17.4 \\
\hline Mymensingh & 29 & 12.0 \\
\hline Rajshahi & 29 & 12.0 \\
\hline Rangpur & 24 & 10.0 \\
\hline Sylhet & 25 & 10.4 \\
\hline \multicolumn{3}{|l|}{ Type of residence } \\
\hline Rural & 83 & 34.4 \\
\hline Urban & 158 & 65.6 \\
\hline \multicolumn{3}{|l|}{ Level of education } \\
\hline No education & 15 & 6.2 \\
\hline Up to Primary & 18 & 7.5 \\
\hline Up to Secondary & 37 & 15.4 \\
\hline Up to Higher Secondary & 33 & 13.7 \\
\hline Above Higher Secondary & 138 & 57.3 \\
\hline \multicolumn{3}{|l|}{ Income status } \\
\hline Low-income & 7 & 2.9 \\
\hline Middle-income & 197 & 81.7 \\
\hline High-income & 37 & 15.4 \\
\hline
\end{tabular}

The majority of the people infected by the SARS-CoV-2 virus had mild to moderate symptoms. Multiple response analyses found that the most prevalent symptoms of the respondents were fever (92.5\%), cough (78.4\%), and sore throat (62.7\%). Olfactory dysfunction (anosmia) or taste disturbances (dysgeusia) was also a cardinal feature. Less common features were congestion (28.2\%) and fatigue. The main presenting gastrointestinal manifestation was diarrhea. Among the subjects, over six percent reported having any severe symptoms such as dyspnea and hypoxia. Moreover, a markedly high proportion of the population had headaches and muscle or body aches (Figure 1).

Among the respondents, 23 percent had pre-existing respiratory complications where asthma and allergic rhinitis were predominant (15.3\% each), followed by pneumonia (Figure 2A). Previous chronic diseases were also present, and hypertension (17.3\%) and diabetes (13.8\%) were the most prevalent. Additionally, cardiovascular diseases (CVD) were the third most prevalent comorbidities (6.7\%). Participants were also found to have underlying metabolic disorders, liver and kidney diseases, among others (Figure 2B).

\section{Non-pharmacological approaches and practices}

Non-pharmacological approaches such as home remedies and practices followed by the COVID-19 patients at home were measured. The majority of the participants reported taking some forms of home remedies such as drinking any hot drink such as tea (85.9\%), inhaling steam/ gargling warm water $(75.1 \%)$, and eating vegetables and fruits (67.6\%) daily, as these are readily available and inexpensive measures. Only a minuscule percentage 
reported that they did not follow those practices when infected. The practice of daily physical exercise was noticed in only 23 percent of respondents, whereas over 47 percent were found not to engage in any physical exercise. Another finding is that people taking vitamin supplements (74.3\%) was more prevalent than people who did not. The non-pharmacological approaches followed by the respondents are summarized in Table 2.

Table 2. Non-pharmacological approaches and practices $(\mathrm{N}=241)$.

\begin{tabular}{|c|c|c|}
\hline Variables & Frequency & Percentage \\
\hline \multicolumn{3}{|c|}{ Eating fruits and vegetables } \\
\hline Daily & 163 & 67.6 \\
\hline Once a week & 21 & 8.7 \\
\hline 3 times a week & 48 & 19.9 \\
\hline Never & 9 & 3.7 \\
\hline \multicolumn{3}{|c|}{ Drinking hot drinks } \\
\hline Daily & 207 & 85.9 \\
\hline Once a week & 9 & 3.7 \\
\hline 3 times a week & 20 & 8.3 \\
\hline Never & 5 & 2.1 \\
\hline \multicolumn{3}{|c|}{ Inhaling steam/gargling warm water } \\
\hline Daily & 181 & 75.1 \\
\hline Once a week & 15 & 6.2 \\
\hline 3 times a week & 30 & 12.4 \\
\hline Never & 15 & 6.2 \\
\hline \multicolumn{3}{|l|}{ Physical exercise } \\
\hline Daily & 56 & 23.2 \\
\hline Once a week & 11 & 4.6 \\
\hline 3 times a week & 60 & 24.9 \\
\hline Never & 114 & 47.3 \\
\hline \multicolumn{3}{|c|}{ Vitamin supplements } \\
\hline Yes & 179 & 74.3 \\
\hline No & 62 & 25.7 \\
\hline Total & 241 & 100 \\
\hline
\end{tabular}

\section{Pharmacological approaches}

Medications consumed for managing the disease have been considered pharmacological approaches. The medicines were selected based on the COVID-19 treatment options recommended in the national guidelines on clinical management of COVID-19 of Bangladesh and CDC guidelines, and the drugs that were reported to be potential therapeutic options [22, 28, 29]. Among the participants, more than $97 \%$ have reported consuming at least one drug. Paracetamol, also known as acetaminophen, was consumed by the largest group of respondents ( $95.9 \%$ ), followed by antihistamines. More than 60 percent of the infected patients consumed antibiotics. A significant proportion also reported taking antiparasitic drugs, ivermectin (12.9\%) and hydroxychloroquine (2.9\%), while a few patients consumed antiviral drugs favipiravir (5.4\%), oseltamivir (2.9\%), and remdesivir (1.7\%). Additionally, nearly 11 percent of the participants took corticosteroids and of them, subjects without any severe symptoms were higher (61.5\%) (Figure 3).

\section{Assessing the impact of various factors that have a significant influence on the recovery time from COVID-19}

Pearson Chi-square test was carried out to determine any significant association of possible study variables and COVID-19 recovery time (measured from the time of being tested positive). Out of 34 probable risk factors, including some socio-demographic, pharmacological, and non-

pharmacological factors that might have an association with recovery time, only seven were found significant at a $10 \%$ level. From the study, it was found that there is a significant association between the recovery time of COVID-19 (presence of no symptom) and geographical distribution ( $p<$ $0.1)$, types of residence, and an education level $(p<0.05)$. Urban people have recovered more early than rural peoples (36.5\% vs. $13.3 \%)$. Significant differences were found among subjects with different educational qualifications. No significant differences were found between subjects who recovered by adopting non-pharmacological and subjects recovered who without taking those except for eating vegetables and fruits daily ( $p<0.1)$. Moreover, moderately significant differences were found between subjects taking supplements and subjects without taking supplements ( $p<0.1$ ). Also, medicine consumption has no significant impact on recovery time from COVID-19. There was a significant association between the recovery time and the presence of diabetes $(p<0.05)$ and CVD $(p<0.1)$. Patients with underlying diabetes or CVD had a late recovery from the disease. (Table 3).

Table 3: Pearson Chi-Square test for assessing the relationship between recovery time from COVID-19 and socio-demographic and home healthcare-seeking behaviors. 


\begin{tabular}{|c|c|c|c|}
\hline Variables & Early recovery (0-14 days) N (\%) & Late recovery (more than 14 days) $\mathrm{N}(\%)$ & P-value \\
\hline \multicolumn{4}{|l|}{ Division } \\
\hline Barishal & $12(5.0)$ & $19(7.9)$ & \multirow{8}{*}{$0.09 *$} \\
\hline Chattogram & $16(6.6)$ & $10(4.1)$ & \\
\hline Dhaka & $12(5.0)$ & $23(9.5)$ & \\
\hline Khulna & $25(10.4)$ & $17(7.1)$ & \\
\hline Mymensingh & $16(6.6)$ & $13(5.4)$ & \\
\hline Rajshahi & $17(7.1)$ & $12(5.0)$ & \\
\hline Rangpur & $8(3.3)$ & $16(6.6)$ & \\
\hline Sylhet & $14(5.8)$ & $11(4.6)$ & \\
\hline \multicolumn{4}{|l|}{ Type of residence } \\
\hline Rural & $32(13.3)$ & $51(21.2)$ & \multirow[t]{2}{*}{$0.01 * *$} \\
\hline Urban & $88(36.5)$ & $70(29.0)$ & \\
\hline \multicolumn{4}{|l|}{ Level of education } \\
\hline No education & $7(2.9)$ & $8(3.3)$ & \multirow{5}{*}{$0.00 * *$} \\
\hline Primary & $3(1.2)$ & $15(6.2)$ & \\
\hline Secondary & $10(4.1)$ & $27(11.2)$ & \\
\hline Higher secondary & $16(6.6)$ & $17(7.1)$ & \\
\hline Tertiary & $84(34.9)$ & $54(22.4)$ & \\
\hline \multicolumn{4}{|l|}{ Diabetes } \\
\hline Yes & $9(3.7)$ & $22(9.1)$ & \multirow[t]{2}{*}{$0.01 * *$} \\
\hline No & $111(46.1)$ & $99(41.1)$ & \\
\hline \multicolumn{4}{|c|}{ Cardiovascular diseases } \\
\hline Yes & $4(1.7)$ & $11(4.6)$ & \multirow[t]{2}{*}{$0.06^{*}$} \\
\hline No & $110(45.6)$ & $116(48.1)$ & \\
\hline \multicolumn{4}{|c|}{$\begin{array}{l}\text { Daily consumption of } \\
\text { fruits and vegetables }\end{array}$} \\
\hline Yes & $88(54.0)$ & $75(46.0)$ & \multirow[t]{2}{*}{$0.06^{*}$} \\
\hline No & $32(41.0)$ & $46(59.0)$ & \\
\hline \multicolumn{4}{|c|}{ Vitamin supplements } \\
\hline Yes & $95(39.4)$ & $84(34.9)$ & \multirow{2}{*}{$0.08^{*}$} \\
\hline No & $9(25.4)$ & $37(35.4)$ & \\
\hline
\end{tabular}

Note: Only significant variables were presented in this table. Here * means significant at $10 \%$ and $* *$ means at $5 \%$

The logistic regression model revealed that type of residence, education level, and underlying diabetes, were the significant factors associated with COVID-19 recovery time (Table 4). More specifically, patients living in urban areas had more chances of recovering early from COVID-19 than rural patients (OR: 3.26, 95\% Cl: 1.19-8.95). Subjects with tertiary education had a statistically significantly lower recovery time of COVID-19 than others. Respondents with primary and secondary education levels had a late recovery than the others. Finally, subjects without previous diabetes had a 2.76 times higher chance of getting cured early than those with diabetes (OR: $2.76,95 \% \mathrm{Cl}: 1.00-7.57)$. From the classification table, it was observed that the correctly predicted accuracy of the logistic regression model was $72.5 \%$ that is almost 72.5 percent of respondents were correctly predicted by this model. Moreover, the Hosmer-Lemeshow goodness-of-fit (GOF) test (value=0.78, P-value=0.99) indicated no evidence of poor fit in the model; hence the model is correctly specified.

Table 4: Factors that have a significant impact on recovery time from COVID-19

\begin{tabular}{lllll}
\hline Variables & Odds ratio & P-value & \multicolumn{2}{c}{$95 \%$ CI } \\
Lower & Upper \\
\hline $\begin{array}{l}\text { Type of residence } \\
\text { Rural }\end{array}$ & $1.00^{\mathrm{a}}$ & & & \\
Urban & 3.26 & 0.02 & 1.19 & 8.95 \\
Level of education & & & & \\
No education & $1.00^{\mathrm{a}}$ & & & \\
Primary & 0.11 & 0.02 & 0.02 & 0.69 \\
Secondary & 0.24 & 0.05 & 0.06 & 0.98 \\
Higher secondary & 0.45 & 0.27 & 0.11 & 1.86 \\
Tertiary (above higher secondary) & 0.98 & 0.97 & 0.28 & 3.40 \\
Diabetes & & & & \\
Yes & $1.00^{\mathrm{a}}$ & & & \\
No & 2.76 & 0.05 & 1.00 & 7.57 \\
\hline
\end{tabular}

Note: $1.00^{\mathrm{a}}$ indicates the reference category

\section{Discussion}

Our study found that the majority of the respondents adopted non-pharmacological approaches such as inhaling steam/ gargling warm water, drinking hot drinks and consuming vegetables and fruits daily. Paracetamol, antihistamines and antibiotics were the highest consumed medicines 
for home treatment. Logistic regression revealed that urban residence level of education and diabetes were the factors associated with recovery time.

Although most participants were reported following the approaches daily, we find no strong association between following non-pharmacological approaches or practices and recovery time. There were no specific studies investigating their effect on recovery time, instead, these approaches were mainly recommended to relieve symptoms associated with COVID-19. For example, gargling saltwater or steam inhalation for soothing sore throat and cleaning mucus in the throat [30]. Previous investigations rejected the claim that gargling salt water or steam inhalation can prevent COVID-19 [31]. Health experts and organizations have been recommending the consumption of vegetables and fruits with proper nutrition to maintain their health and boost their immunity [23]. A significant association was observed between daily consumption of vegetables and fruits and recovery time, where subjects who consumed daily recovered early. A study found that intake of vegetables and fruits is associated with lower COVID-19 infection and mortality rate. Developed countries with higher vegetable and fruit consumption had lower death rates, whereas both infection and death rates from COVID-19 were lower in developing countries with higher consumption [32]. Daily physical activity is essential for health and wellbeing since almost all countries imposed movement restrictions, and "work from home" has been adopted as a new norm. The WHO has recommended regular exercise for a certain period, and this, according to them, can reduce the risk of obesity, blood, and type 2 diabetes. These diseases are the risk factors for COVID-19 [21,33]. Consumption of vitamin supplements was higher among the survey participants. We found an association between vitamin supplement consumption and recovery time $(p<0.1)$, but it was not strong. Nevertheless, many vitamins have gained considerable importance for their pharmacological properties. Clinical trials on the efficacy of vitamins since the outbreak, are yet to provide any findings.

There were no strongly recommended evidence-based therapeutic options for COVID-19, albeit some drugs showed promising results [34]. Many asymptomatic cases occurred, and nearly $80 \%$ of infected individuals recovered without particular medicine and treatment [25]. The national COVID19 management guidelines recommended paracetamol and antihistamines to manage mild to moderate patients [22]. Fever was the predominant symptom whereas muscle/body pain, and headaches were also present among many and it might contribute to the elevated consumption of paracetamol. Antihistamines especially fexofenadine, (a second-generation antihistamine) consumption were also higher among subjects. Since many allergic and respiratory symptoms have similarities with COVID-19, these have been recommended to treat the patients. The percentage of such symptoms as cough, sore throat and rhinorrhea is also higher among the study participants. Several studies suggested that antihistamines are effective for primary care of the disease and prevent the disease from being severe in older patients [35, 36]. The rate of antibiotics consumption was considerably high among the participants. Although COVID-19 is a viral disease, many antibiotics have gained utmost priority as a therapeutic option because of their efficacy against respiratory infection even for severe and critical patients [37, 38]. Antibiotics are also among the popular medications used to relieve COVID-19 symptoms among self-medicated patients and it is alarming news that people are consuming antibiotics as prophylactic treatment without any symptom and prescription [39]. The respondents also utilized antiparasitic drugs, mainly ivermectin. Clinical trials conducted in different countries including Bangladesh showed that ivermectin without and with the combination of other drugs can improve symptoms and reduce mortality, though more evidence is needed on its efficacy $[40,41]$. One study found that a significant number of Bangladeshi populations used ivermectin to relieve COVID-19 symptoms and prophylaxis [42]. Corticosteroids and antiviral drugs were the least consuming medicine among our participants. However, it implies that many patients had taken corticosteroids without any severity which could be dangerous for them if not used for other complications. Favipiravir and oseltamivir were the most used antiviral medications among the subjects while a small percentage reported taking remdesivir. Remdesivir and favipiravir have questionable effectiveness. Favipiravir is an approved drug for treating influenza and has been found associated with SARS-CoV-2 clearance if treated early [34]. Favipiravir has been effective for mild and moderate patients, albeit clinical trials are going on for more clinical evidence in favor of the drug [34, 43].

Logistic regression revealed that place of residence is associated with early COVID-19 recovery, and respondents from the urban areas recovered earlier. Previous studies found that urban people had more knowledge of the disease and followed the hygiene practices more often [44, 45]. Significant differences were found between education level and recovery time. The highest early recovery was observed in respondents having tertiary level education, but subjects with no education had an earlier recovery than those with primary or secondary education. The reason behind this discrepancy is, possibly, that people with no education had done their COVID-19 test late. They may go for a test after becoming a bit severe, and we only reported the recovery time from the day they tested positive. Diabetes and hypertension were prevalent pre-existing chronic diseases. Studies showed that diabetes and hypertension were also the most prevailing comorbidities in hospitalized patients [46, 47]. Our study found an association between recovery and underlying diabetes and CVD and had a late recovery, while underlying diabetes is more significantly associated with delayed recovery. A meta-analysis conducted by Bolin Wang et al. delineated that kidney, liver diseases, and even malignancies were not associated with elevated risk, but diseases like hypertension, diabetes and cardiovascular diseases were significantly associated with a higher risk in COVID-19 patients [48]. However, it is yet to be confirmed which comorbidities can lead to poor prognosis because the respondents were not hospitalized, and the research team did not collect the exact medication itinerary.

Though the COVID-19 pandemic has become very common globally, its pathology and genetic makeup are not clearly understood because of its continuous mutations. Moreover, one of the serious concerns is that the genome of SARS-CoV-2 has evolved in numerous countries, including Bangladesh. Health experts recommend that the patients should take treatment at home if hospitalization is not necessary. The disease has become a 'new normal,' and health experts and epidemiologists have suggested adapting to this. Therefore, traditional non-pharmacological and pharmacological approaches were considered convenient contrivances. Primary care treatment and management approaches are considered of utmost importance since the onset of the disease and this study may be helpful to know the commonly used approaches and medicine by COVID-19 
patients as home care. Additionally, the non-pharmacological approaches are cheap, readily available and safer to use and have been a part of home management for various diseases. The country is facing difficulty providing treatment facilities for all the patients. Moreover, even though the patients required hospital facilities, they have less trust in health systems for various reasons [11, 12]. So, mild and moderate patients who would mostly recover without special treatment may adopt these approaches to suppress the disease from being severe. Our study demonstrated that home management and care got enormous concern for the treatment of this novel respiratory disease especially for patients with mild and moderate symptoms. A resource-limited country like Bangladesh needs to emphasize more on prevention and primary care. Nevertheless, this study has limitations, and laboratory experiments remain to be performed on how the adopted pharmacological and no-pharmacological approaches impact recovery time. Also, long-term follow-up studies of the patients are needed.

\section{Limitations}

The most important limitation is that the causal relationship cannot be established from a cross-sectional study design. Secondly, a small sample size, convenience sampling, and a limited number of questions may not establish statistical significance. Thirdly, there may be bias since it is an online-based survey where respondents have reported by themselves and only people with internet access participated in the study.

\section{Conclusion}

The COVID-19 pandemic is indeed one of the greatest disasters in the history of humankind. Bangladesh is hardly capable of tackling the disease properly with its low-resource settings. So primary care treatment is important to suppress the disease from being severe. The purpose of this study is to explore various readily available remedies, approaches, and medicine to cure the COVID-19 at home. The majority of respondents experience mild to moderate symptoms and adopted non-pharmacological approaches more often than consuming medications. These approaches can be adopted in the early stage to reduce the disease severity and may be effective for mild and moderate patients, albeit significant impacts were not observed on recovery time. Also, future researches need to be performed on the effect of different measures on reducing the severity of the disease.

\section{Abbreviations}

SARS-CoV-2: Severe Acute Respiratory Syndrome Coronavirus-2; COVID-19: Coronavirus disease-2019; WHO: World Health Organization; CVD: Cardiovascular diseases.

\section{Declarations}

\section{Ethics approval and consent to participate}

Ethical Review Committee of the Public Health Foundation, Bangladesh (Ref: PHFBD/ERC/03/2021) approved this study.

\section{Consent for publication}

Not applicable

\section{Availability of data and materials}

The supporting datasets generated/ analyzed during this study are available from the corresponding author on reasonable request.

\section{Competing interests}

The author declares no competing interests.

\section{Funding}

No funding was received for this study

\section{Author contribution}

AAN, MSI- Conceptualization, Methodology, Validation, Formal analysis, Investigation, Visualization, Writing - original draft, Writing - review \& editing MSH - Methodology, Validation, Formal analysis, Visualization, Writing - review \& editing

SS, JEE, MAN, MS, RIM, NS- Methodology, Validation, Investigation, Visualization, Writing - review \& editing.

TJ, SS and MMR- Conceptualization, Methodology, Validation, Visualization, Writing - review \& editing, Supervision, Project administration.

\section{Acknowledgment}


The authors are grateful to the Department of Genetic Engineering and Biotechnology, Jashore University of Science and Technology and the Public Health Foundation of Bangladesh for ethical approval and technical support.

\section{References}

1. Al Noman A, Islam MS, Sana S, Mondal P, Meem RI, Rana S, et al. A review of the genome, epidemiology, clinical features, prevention, and treatment scenario of COVID-19: Bangladesh aspects. Egypt J Bronchol. 2021;15. doi:10.1186/s43168-021-00053-2.

2. WHO Coronavirus (COVID-19) Dashboard I WHO Coronavirus (COVID-19) Dashboard With Vaccination Data. https://covid19.who.int/. Accessed 2 Jun 2021

3. Wang L, Wang Y, Ye D, Liu Q. Review of the 2019 novel coronavirus (SARS-CoV-2) based on current evidence. Int J Antimicrob Agents. 2020;55:105948. doi:10.1016/j.ijantimicag.2020.105948.

4. IEDCR. https://old.iedcr.gov.bd/. Accessed 2 Jun 2021.

5. Coronavirus disease (COVID-2019) Bangladesh situation report 58. https://www.who.int/bangladesh/emergencies/coronavirus-disease-(covid19)-update/coronavirus-disease-(covid-2019)-bangladesh-situation-reports. Accessed 15 Apr 2021

6. Bangladesh imposes restrictions to curb new Covid-19 wave | Dhaka Tribune. https://www.dhakatribune.com/bangladesh/2021/03/29/govtimposes-fresh-restrictions-amid-covid-surge. Accessed 1 Apr 2021.

7. Haque MF, Rahman MM, Alif SM, Akter E, Barua S, Paul GK, et al. Estimation and prediction of doubling time for COVID-19 epidemic in Bangladesh: a study of first 14 month's daily confirmed new cases and deaths. Glob Biosecurity. 2021;3. doi:10.31646/gbio.91.

8. Coronavirus disease (COVID-2019) Bangladesh situation report 57. https://www.who.int/bangladesh/emergencies/coronavirus-disease-(covid19)-update/coronavirus-disease-(covid-2019)-bangladesh-situation-reports. Accessed $11 \mathrm{Apr} 2021$.

9. Coronavirus disease (COVID-2019) Bangladesh situation reports-56. https://www.who.int/bangladesh/emergencies/coronavirus-disease-(covid19)-update/coronavirus-disease-(covid-2019)-bangladesh-situation-reports. Accessed $11 \mathrm{Apr} 2021$.

10. Three dedicated hospitals stop COVID-19 services. https://www.newagebd.net/article/116529/three-dedicated-hospitals-stop-covid-19-services. Accessed 25 Sep 2020

11. Joarder T, Nahian M, Khaled B, Zaman S. Trust in the Bangladeshi Health System During the COVID-19 Pandemic: A Mixed-Methods Exploration. 2020. doi:10.21203/rs.3.rs-117196/v1.

12. Joarder T, Khaled MNB, Joarder MAI. Urban educated group's perceptions of the COVID-19 pandemic management in Bangladesh: a qualitative exploration. F1000Research. 2021;10:170. doi:10.12688/f1000research.28333.2.

13. COVID-19 deaths cross 5,000 in Bangladesh. https://www.newagebd.net/article/116982/covid-19-deaths-cross-5000-in-bangladesh. Accessed 25 Sep 2020

14. Beyond Recovery: Towards 2030 | UNDP in Bangladesh. https://www.bd.undp.org/content/bangladesh/en/home/coronavirus/support-tonational-response.html. Accessed 5 Sep 2020.

15. Scudellari M. How the pandemic might play out in 2021 and beyond. Nature. 2020;584:22-5.

16. Coronavirus: Fake and misleading stories that went viral this week - BBC News. https://www.bbc.com/news/52124740. Accessed 20 Feb 2021.

17. No, drinking water doesn't kill coronavirus - BBC Future. https://www.bbc.com/future/article/20200319-covid-19-will-drinking-water-keep-yousafe-from-coronavirus. Accessed 20 Feb 2021.

18. Panic-buying creates shortage of 'Covid-19 drugs' in the market | Dhaka Tribune. https://www.dhakatribune.com/health/coronavirus/2020/06/21/panic-buying-creates-shortage-of-covid-19-drugs-in-the-market. Accessed 20 Feb 2021.

19. Local pharmaceuticals producing anti-flu drug that holds hope of Covid-19 cure | The Daily Star. https://www.thedailystar.net/business/news/beacon-beximco-producing-anti-flu-drug-holds-hope-covid-19-cure-1889713. Accessed 20 Apr 2021.

20. Symptoms of Coronavirus | CDC. https://www.cdc.gov/coronavirus/2019-ncov/symptoms-testing/symptoms.html. Accessed 21 Jan 2021.

21. Natalucci V, Carnevale Pellino V, Barbieri E, Vandoni M. Is It Important to Perform Physical Activity During Coronavirus Pandemic (COVID-19)? Driving Action for a Correct Exercise Plan. Front Public Heal. 2020;8:602020. doi:10.3389/fpubh.2020.602020.

22. National Guidelines on Clinical Management of Coronavirus Disease 2019 (COVID-19): Version 4.0. https://mofa.portal.gov.bd/sites/default/files/files/mofa.portal.gov.bd/page/ad1f289c_47cf_4f6c_8dee_887957be3176/National Guidelines on Clinical Management of Covid-19- DGHS.pdf. Accessed 11 Mar 2021.

23. WHO EMRO | Nutrition advice for adults during the COVID-19 outbreak | COVID-19 | Nutrition site. https://www.emro.who.int/nutrition/news/nutrition-advice-for-adults-during-the-covid-19-outbreak.html. Accessed 13 Mar 2021.

24. The Latest on the Covid-19 Global Situation \& Long-Term Sequelae Long-term effects of COVID-19. https://www.who.int/docs/defaultsource/coronaviruse/risk-comms-updates/update-36-long-term-symptoms.pdf?sfvrsn=5d3789a6_2. Accessed 12 Mar 2021. 
25. Report of the WHO-China Joint Mission on Coronavirus Disease 2019 (COVID-19). https://www.who.int/publications/i/item/report-of-the-whochina-joint-mission-on-coronavirus-disease-2019-(covid-19). Accessed 12 Mar 2021.

26. Rahman MM, Hamiduzzaman M, Akter MS, Farhana Z, Hossain MK, Hasan MN, et al. Frailty indexed classification of Bangladeshi older adults' physio-psychosocial health and associated risk factors- a cross-sectional survey study. BMC Geriatr. 2021;21:1-10. doi:10.1186/s12877-02001970-5.

27. The Rise of the Middle Class in the People's Republic of China | Asian Development Bank. https://www.adb.org/publications/rise-middle-classpeoples-republic-china. Accessed 3 Apr 2021.

28. Teimury A, Khaledi EM. Current options in the treatment of covid-19: A review. Risk Management and Healthcare Policy. 2020;13:1999-2010. doi:10.2147/RMHP.S265030.

29. Therapeutic Management | COVID-19 Treatment Guidelines. https://www.covid19treatmentguidelines.nih.gov/therapeutic-management/. Accessed 25 Mar 2021.

30. Treating Coronavirus at Home | University of Maryland Medical System. https://www.umms.org/coronavirus/what-to-know/treat-covid-at-home? _cf_chl_jschl_tk_=92bddaee15358e3ecb393ad5d97f10ae7cc72186-1619211516-0-

AU74edCdpW24WPluQb9vWXXfz0qAL5X2edwc20jaGDI0t9FORrsjh5bCweG1krML2inR5kZ46wThZ2xaikLzX4Wv7jeG0o1DifG6Pp9we4HXxtmEOU. Accessed 14 Apr 2021.

31. Barati F, Pouresmaieli M, Ekrami E, Asghari S, Ziarani FR, Mamoudifard M. Potential Drugs and Remedies for the Treatment of COVID-19: A Critical Review. Biological Procedures Online. 2020;22:15. doi:10.1186/s12575-020-00129-1.

32. Yedjou CG, Alo RA, Liu J, Enow J, Ngnepiepa P, Long R, et al. Chemo-Preventive Effect of Vegetables and Fruits Consumption on the COVID-19 Pandemic. J Nutr Food Sci. 2021;4. http://www.ncbi.nlm.nih.gov/pubmed/33884222. Accessed 15 Apr 2021.

33. HealthyAtHome - Physical activity. https://www.who.int/news-room/campaigns/connecting-the-world-to-combatcoronavirus/healthyathome/healthyathome--physical-activity. Accessed 14 Apr 2021.

34. Indari O, Jakhmola S, Manivannan E, Jha HC. An Update on Antiviral Therapy Against SARS-CoV-2: How Far Have We Come? Frontiers in Pharmacology. 2021;12:133. doi:10.3389/fphar.2021.632677.

35. Morán Blanco Jl, Alvarenga Bonilla JA, Homma S, Suzuki K, Fremont-Smith P, Villar Gómez de las Heras K. Antihistamines and azithromycin as a treatment for COVID-19 on primary health care - A retrospective observational study in elderly patients. Pulm Pharmacol Ther. 2021;67:101989. doi:10.1016/j.pupt.2021.101989.

36. Reznikov LR, Norris MH, Vashisht R, Bluhm AP, Li D, Liao YSJ, et al. Identification of antiviral antihistamines for COVID-19 repurposing. Biochem Biophys Res Commun. 2021;538:173-9.

37. Morán Blanco JI, Alvarenga Bonilla JA, Homma S, Suzuki K, Fremont-Smith P, Villar Gómez de las Heras K. Antihistamines and azithromycin as a treatment for COVID-19 on primary health care - A retrospective observational study in elderly patients. Pulm Pharmacol Ther. 2021;67:101989. doi:10.1016/j.pupt.2021.101989.

38. Chedid M, Waked R, Haddad E, Chetata N, Saliba G, Choucair J. Antibiotics in treatment of COVID-19 complications: a review of frequency, indications, and efficacy. J Infect Public Health. 2021;14:570-6.

39. Nasir M, Chowdhury ASMS, Zahan T. Self-medication during COVID-19 outbreak: a cross sectional online survey in Dhaka city. Int J Basic Clin Pharmacol. 2020;9:1325. doi:10.18203/2319-2003.ijbcp20203522.

40. Bangladesh: Ivermectin shows promise in treating virus. https://www.aa.com.tr/en/asia-pacific/bangladesh-ivermectin-shows-promise-intreating-virus/2068885. Accessed 22 Apr 2021.

41. Kaur H, Shekhar N, Sharma S, Sarma P, Prakash A, Medhi B. Ivermectin as a potential drug for treatment of COVID-19: an in-sync review with clinical and computational attributes. Pharmacological Reports. 2021;1:3. doi:10.1007/s43440-020-00195-y.

42. Ahmed I, Hasan M, Akter R, Sarkar BK, Rahman M, Sarker MS, et al. Behavioral preventive measures and the use of medicines and herbal products among the public in response to Covid-19 in Bangladesh: A cross-sectional study. PLoS One. 2020;15:e0243706. doi:10.1371/journal.pone.0243706.

43. Dabbous HM, El-Sayed MH, El Assal G, Elghazaly H, Ebeid FFS, Sherief AF, et al. Safety and efficacy of favipiravir versus hydroxychloroquine in management of COVID-19: A randomised controlled trial. Sci Rep. 2021;11:7282. doi:10.1038/s41598-021-85227-0.

44. Karim A, Akter M, Mazid AT, Pulock OS, Aziz TT, Hayee S, et al. Knowledge and Attitude towards COVID-19: A Cross Sectional Study in Bangladesh through Phone and Online Survey. J Clin Exp Investig. 2020;11:em00757.

45. Hossain MA, Jahid MIK, Hossain KMA, Walton LM, Uddin Z, Haque MO, et al. Knowledge, attitudes, and fear of COVID-19 during the Rapid Rise Period in Bangladesh. PLoS One. 2020;15:e0239646. doi:10.1371/journal.pone.0239646.

46. Richardson S, Hirsch JS, Narasimhan M, Crawford JM, McGinn T, Davidson KW, et al. Presenting Characteristics, Comorbidities, and Outcomes among 5700 Patients Hospitalized with COVID-19 in the New York City Area. JAMA - J Am Med Assoc. 2020;323:2052-9.

47. Al-Salameh A, Lanoix J, Bennis Y, Andrejak C, Brochot E, Deschasse G, et al. Characteristics and outcomes of COVID-19 in hospitalized patients with and without diabetes. Diabetes Metab Res Rev. 2021;37:e3388. doi:10.1002/dmrr.3388. 
48. Wang B, Li R, Lu Z, Huang Y. Does comorbidity increase the risk of patients with covid-19: Evidence from meta-analysis. Aging (Albany NY). 2020;12:6049-57. doi:10.18632/AGING.103000.

\section{Figures}

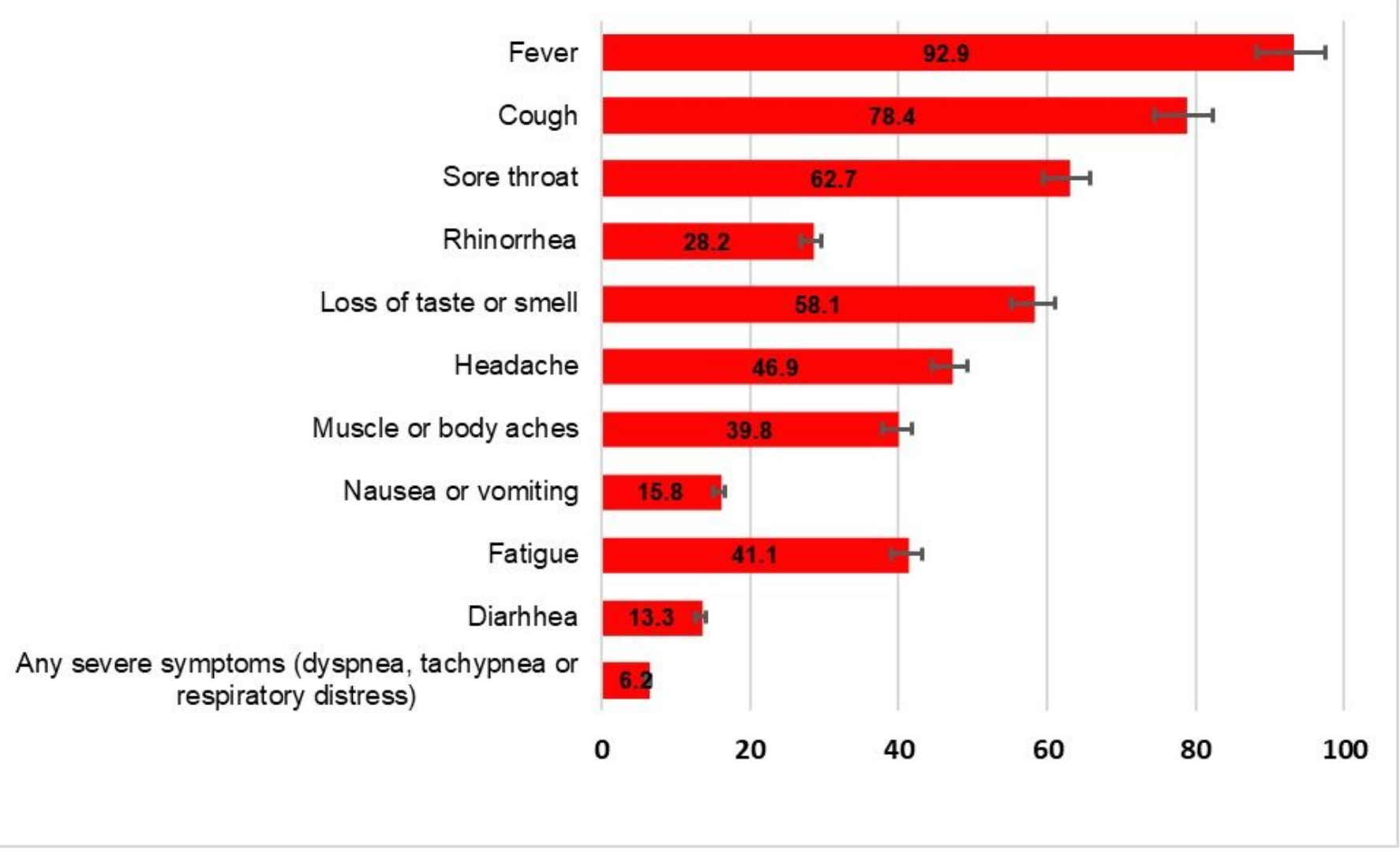

Figure 1

Symptoms of COVID-19 among respondents

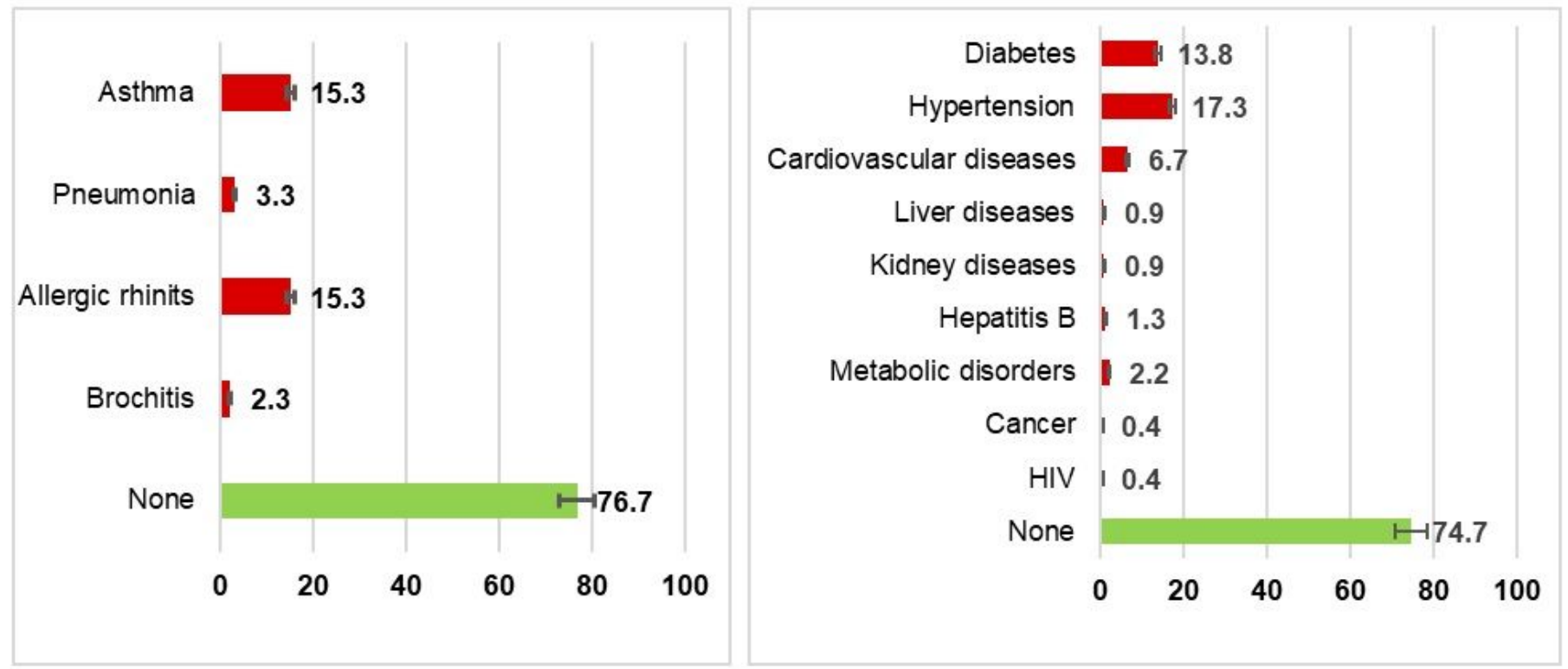

Figure 2

Presence of comorbidities A. respiratory complications, B. chronic diseases 


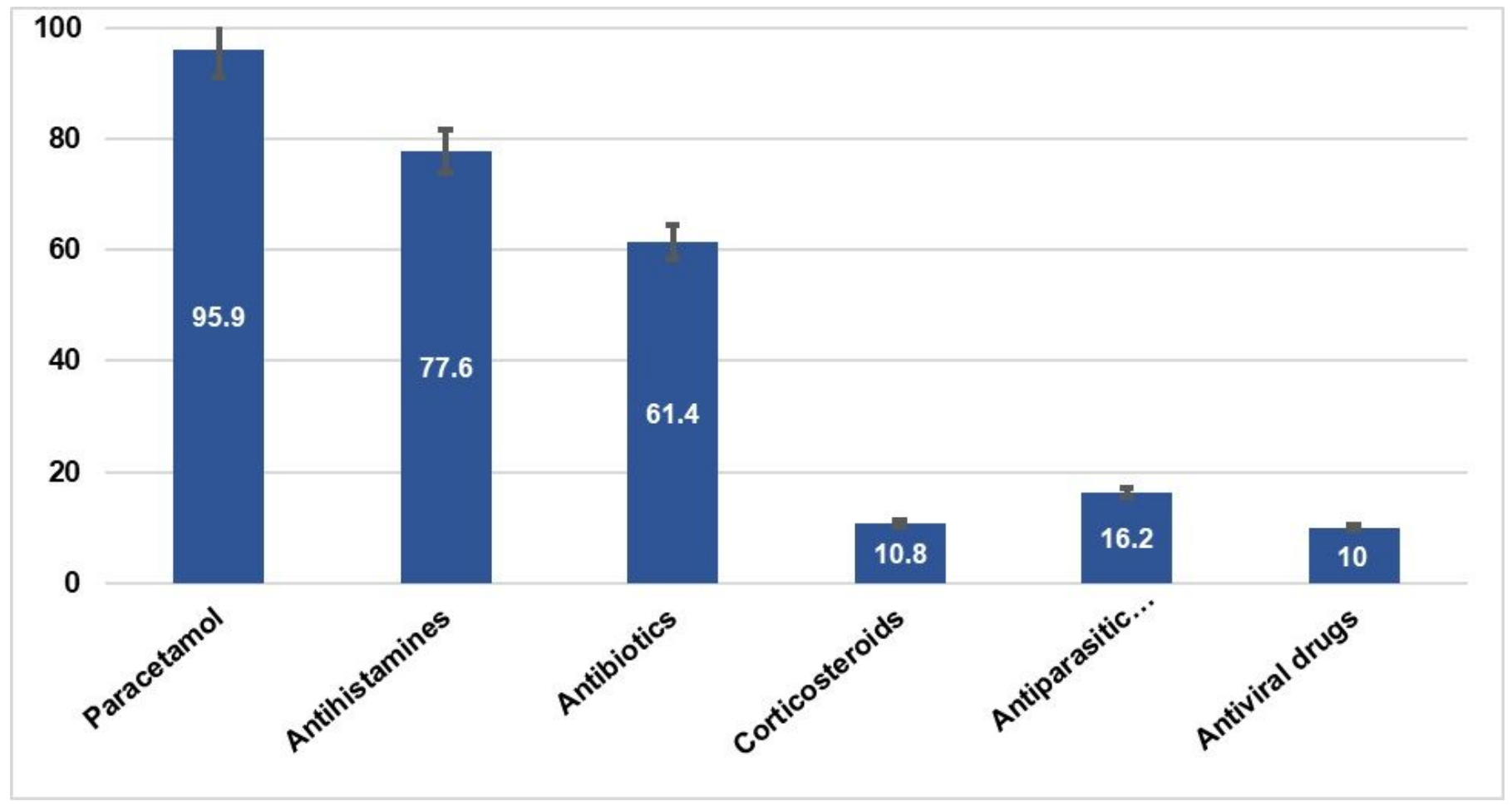

Figure 3

Medicine consumed by respondents 